\title{
Familiarity and nameability do not affect picture detection
}

\author{
MURIEL BOUCART \\ Université Paris V René Descartes, Paris, France \\ and \\ GLYN W. HUMPHREYS \\ University of Birmingham, Birmingham, England \\ (Claude Bonnet, Sponsor)
}

\begin{abstract}
It has recently been suggested that the familiarity of a stimulus can affect early sensory processes involved in their detection. This hypothesis was tested in a detection task using fragmented forms varying in familiarity and their structural properties but equivalent in their spatial frequency content. No effect of familiarity or structure was found on the detectability of the stimuli. Possible reasons for the familiarity effect observed in previous detection studies are discussed.
\end{abstract}

Recent data suggest that the familiarity of a visual stimulus can influence its detectability. For instance, it has been reported that a face presented in a normal upright orientation is detected more accurately than a scrambled or an inverted face (Purcell \& Stewart, 1986, 1988), and that words are detected more easily than orthographically regular and orthographically irregular nonwords (Doyle \& Leach, 1988). These results suggest that the "detectability of a stimulus is affected not only by its psychophysical properties ... but also by its informational properties (whether the stimulus forms a pattern that is meaningful for the observer)" (Purcell \& Stewart, 1988, p. 355).

These results are intriguing because they contradict the "identity assumption" concerning visual processing - that is, that our awareness of visual stimuli directly reflects the temporal order of stimulus encoding (see Marcel, 1983).

There is now a considerable amount of evidence showing that early sensory levels of processing involve a decomposition of the spatiotemporal distribution of luminance that constitutes the physical stimulus into elementary features such as wavelength, spatial frequencies, and orientations (see Bonnet, 1989; De Valois \& De Valois, 1980, 1988; Ginsburg, 1978; Graham, 1981, for reviews). The processing of higher order formal, semantic, and phonological information occurs some time after the extraction of the physical characteristics of a stimulus (Bonnet, 1986; Riddoch \& Humphreys, 1987). However, the face-detection and word-detection effects suggest that, even if physical properties are encoded prior to semantic

This research was supported by grants from the British Council and Naturalia and Biologia to the first author. Address reprint requests and correspondence to M. Boucart, Laboratoire de Psychologie Experimentale, Université Paris V René Descartes, C.N.R.S. (URA 316), 28 rue Serpente, 75006 Paris, France. properties, the recovery of stimulus information for conscious detection does not reflect the processing order.

In the present experiment, we examined the generality of the effects of familiarity on detection by using pictorial representations of object stimuli varying on two parameters: the level of structuration of the form (the presence of properties of collinearity and closure) and the familiarity of the figure. One way to manipulate these two parameters is to use fragmented forms, since well- and poorly structured forms can be elaborated by permutations of the fragments. It also turns out that well-structured forms are identifiable, whereas poorly structured forms are not (see Biederman, 1987). For each pair, the global shape, the location of the local densities of fragments, and the fragments themselves were the same, and, as a consequence, the Fourier spectra of the forms were very similar as assessed by a two-dimensional fast Fourier transform (2D FFT) performed on the stimuli. However, one member of each pair was structured on the properties of collinearity and closure, while the other was not. To assess whether identifiability or structuration was important, well-structured forms were separated according to how easily nameable they were.

The detection paradigm employed was the same as that used by Purcell and Stewart (1988). Subjects were asked to judge if the target had been presented on the left or the right of a fixation point. The experiment thus tested the generality of the detection advantage for familiar stimuli (from faces and words to pictures) using stimuli whose structural properties were also tightly constrained.

\section{EXPERIMENT 1: NAMING TASK}

\author{
Method \\ Stimuli. The stimuli were 26 pairs of well/poorly structured frag- \\ mented forms derived from outline drawings of familiar objects. Each
}


stimulus was elaborated from a limited set of fragments $(n=16)$. The global shape, the location of the local densities of fragments, and the fragments themselves were the same for each pair. The two types of stimuli differed on the structural properties of convexity, collinearity, and closure of the elements of the external and internal contours. The percentage of represented contour (relative to the outline drawing), which is an estimate of the collinearity and closure of elements, varied between $47 \%$ and $53 \%$ for well-structured forms and between $16 \%$ and $18 \%$ for poorly structured forms. As can be seen in Figure 1, the location of the fragments was exactly the same for the two versions of fragmented forms. The fragments differed only in orientation; the fragments of the poorly structured forms were rotated in order to reduce the property of convexity and, as a consequence, to minimize the collinearity and closure between elements.

Procedure. The stimuli were presented in black on white cards. They were displayed on an Electronics Development three-field tachistoscope. At a viewing distance of $50 \mathrm{~cm}$, the angular size of the stimuli was $2.86^{\circ}$ horizontally and vertically. The angular size of the visual field was $17.19^{\circ}$ horizontally and $12.6^{\circ}$ vertically. The 26 stimuli of each version were sequentially presented at the center of the visual field. The display was immediately followed by a mask, which was also composed of fragments varying in orientation, size, and shape. The angular size of the mask was the same as the visual field. The luminance of each of the three fields-fixation, stimulus, and mask-was fixed at $20 \mathrm{FtL}$. They were six blocks of 26 stimuli, each determined by the exposure duration of the stimuli $(20,30,40,50,60$, or $70 \mathrm{msec})$. This ascending method was used to test the exposure duration at which the stimuli became identifiable. The 26 stimuli were repeated at each exposure duration in order to test the consistency of the names they were assigned. The duration of the mask was fixed at $100 \mathrm{msec}$. The subjects' task was to name the presented form. The subjects were told to try to give an exact name, but that a category name (e.g., animal, fruit, vehicle) was also acceptable as correct identification. They were also told to respond with "nothing" if they could not give a name immediately after the display. The 26 figures were maintained in the six blocks even if they were identified, in order to test the consistency of the naming responses.

Subjects. Eighteen subjects with normal or corrected-to-normal vision participated in the experiment. They were subdivided in two groups of 9 subjects each and randomly assigned to the well and poorly structured versions. Structuration was varied as a between-subject factor to minimize carryover between identifying the two members of each pairing.

\section{Results}

No figures were identified in the first $(20-\mathrm{msec})$ block. Accordingly, this block was removed from the analysis of variance. The analysis was carried out with the five remaining blocks as a within-subject factor and the type of stimulus as a between-subject factor. The dependent variable was the percentage of correct identification. Only names given by at least $80 \%$ of the subjects and repeated across the five blocks were taken into consideration.

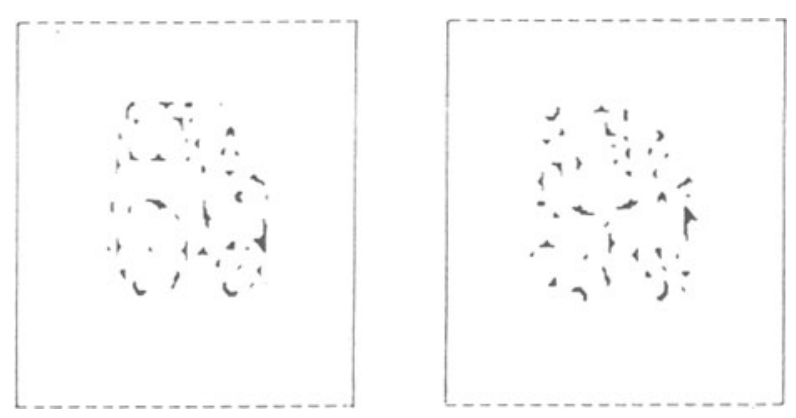

Figure 1. An example of a pair well/poorly structured fragmented forms used in the present study.
The percentage of correctly named stimuli, including both exact and category names, was higher for the wellstructured version $(\mathbf{4 7 . 5 \%})$ than for the poorly structured version $(25.7 \%)[F(1,16)=9.2, p<.01]$. This percentage increased with the increase in exposure time for both the well-structured forms [29.6\%, $41.4 \%, 50.4 \%$, $58.1 \%$, and $60.6 \% ; F(4,32)=17.6, p<.001]$ and the poorly structured forms $[9.8 \%, 20.9 \%, 29 \%, 33.2 \%$, and $35.8 \% ; F(4,32)=20.2, p<.001]$. No interaction was found between type of form and block.

Eight pairs of well/poorly structured forms were selected from this experiment. For well-structured forms, four stimuli (elephant, strawberry, rabbit, apple) were classified as "easily nameable." Their percentages of correct naming were $27.7,47,66.5,66.5$, and 75 , respectively, for the five exposure durations. Four other forms (tractor, sailboat, tortoise, car front) were classified as "hardly nameable." Their percentages of correct naming were $0,0.5,16.7,25$, and 25 , respectively, for the five exposure durations. The selected poorly structured stimuli were the eight corresponding figures. Their percentages of correct naming were 1.3, 6.3, 12.3, 17.9, and 19.3, respectively, for the five durations. The difference in the percentage of correct naming between the easily and hardly nameable forms of the well-structured version was significant $[F(1,16)=11.5, p<.001]$, as was the difference between well- and poorly structured forms $[F(1,16)=14, p<.01]$.

\section{EXPERIMENT 2: DETECTION}

\section{Method}

Stimuli. The stimuli were the eight selected pairs of fragmented forms. Procedure. The stimuli were displayed on the same tachistoscope as in the identification experiment. The luminance of the three fields and the angular sizes of the visual field, the stimuli, and the mask were the same as in the previous experiment. As in the Purcell and Stewart (1986, 1988) studies, a two-alternative spatial forced-choice detection procedure was used. The 16 stimuli were randomly presented on the left or the right of the fixation point. The stimuli were centered $2^{\circ}$ from fixation. The exposure duration of the stimulus was fixed at $5 \mathrm{msec}$. This duration was chosen on the basis of the results of a preliminary experiment performed with 2 subjects. The stimuli used contain a great amount of energy, and all of the stimuli could be detected within $10 \mathrm{msec}$, even with the mask immediately following the display. After an interstimulus interval (ISI) adjusted for each subject, a mask was presented for $100 \mathrm{msec}$. A 2D FFT performed on the mask and on the stimuli showed that the difference between the spectrum of the figure and the spectrum of the mask was equal to zero. The stimuli were thus completely masked. The subjects gave their response by pressing either a left or a right key. They were instructed to respond on each trial even if they had to guess. The responses were recorded by an APPLE II + computer.

The first part of the experiment was devoted to the determination of the ISI necessary for the subjects to reach a performance level between $65 \%$ and $75 \%$ correct detections (averaged across all stimuli). A descending method of limits was used. This session was performed in blocks of 32 trials. The ISI started at $25 \mathrm{msec}$ and was decreased in 3-msec steps at the beginning, and then in 2- or 1-msec steps until the percentage of correct detections reached criterion. When this level was reached, the block of 32 trials was repeated three times to ensure that performance did not vary. Using this procedure, the ISI was fixed at $10 \mathrm{msec}$ for 2 subjects, $11 \mathrm{msec}$ for 1 subject, $15 \mathrm{msec}$ for 1 subject, and $20 \mathrm{msec}$ for 2 subjects.

The determination of the ISI was followed by six experimental blocks of 64 trials each, including 32 left and 32 right trials. Each block of 
Table 1

Mean Percentage of Correct Detections Averaged across Blocks for the 6 Subjects as a Function of the Type of Stimuli

\begin{tabular}{cccccccc}
\hline & \multicolumn{3}{c}{ Blocks 1-3 } & & \multicolumn{3}{c}{ Blocks 4-6 } \\
\cline { 2 - 4 } \cline { 6 - 7 } Subject & WSEN & WSHN & PS & & WSEN & WSHN & PS \\
\hline 1 & 64.5 & 66.6 & 61.4 & & 68.7 & 69.0 & 59.5 \\
2 & 60.4 & 56.2 & 67.7 & & 56.2 & 66.6 & 64.6 \\
3 & 74.9 & 62.5 & 68.8 & & 77.0 & 68.7 & 70.8 \\
4 & 79.1 & 77.0 & 65.0 & & 62.5 & 58.3 & 58.3 \\
5 & 54.2 & 60.4 & 63.6 & & 79.1 & 66.6 & 65.6 \\
6 & 68.7 & 62.5 & 71.8 & & 68.7 & 70.8 & 76.0 \\
$M$ & 66.9 & 64.2 & 66.4 & & 68.7 & 66.7 & 65.8 \\
SD & 8.4 & 6.5 & 3.4 & & 7.8 & 4.0 & 6.1 \\
\hline
\end{tabular}

Note-WSEN = well-structured, easily nameable stimuli; WSHN = well-structured, hardly nameable stimuli; PS = poorly structured.

32 trials was composed of eight well-structured forms (four easily nameable and four hardly nameable) and eight poorly structured forms which were presented two times. No feedback was given. The experiment was run in a dark room on 3 separate days ( 1 for the determination of the ISI and 2 for the experimental blocks), three blocks of 64 trials at a time preceded by 32 practice trials. Each session lasted about $1 \mathrm{~h}$.

Subjects. Six postgraduate students from Birkbeck College, London University, with normal or corrected-to-normal vision, took part in the experiment. They were paid $£ 8$ for their participation.

\section{Results}

An analysis of variance was conducted on the percentage of correct detections. The factors were the structuration of the form, its nameability, and the repetition. The results are presented in Table 1 .

There was no significant difference $(F<1)$ between the types of stimuli: well-structured easily nameable $(67.7 \%)$, hardly nameable $(65.4 \%)$, and poorly structured $(66 \%)$. There was also no significant main effect of repetition and there was no interaction between the experimental factors.

\section{DISCUSSION}

The results show that neither the organizational properties of the stimuli nor their identifiability influenced their detection. This was true for all subjects at all levels of stimulus repetition. This finding raises the question of why we failed to find any sign of a benefit from the well-structured and nameable forms when previous positive effects of familiarity on detection have been observed. First, there are several methodological differences between our study and those of Doyle and Leach (1988) and Purcell and Stewart $(1986,1988)$. We used a mask containing very similar form information to that present in targets. Purcell and Stewart used a light flash mask (1986) and an overlapping letter mask (1988), and Doyle and Leach used a letter-like pattern. It is possible that the recovery of stimulus information under random noise masking differs from that under pattern masking (e.g., see Turvey, 1973; see Humphreys \& Bruce, 1989, for a recent review), and that high-level information is important under pattern-masking conditions (see Marcel, 1983). Purcell and Stewart (1986) reported no familiarity effect with a light flash. However, to the extent that similar form information was present in the targets and mask used in the present study, we would expect processing to be equivalent to that found under pattern-masking conditions, where familiarity effects on detection have been reported.

A second possible factor is the exposure durations used in the studies reporting positive effects. The stimulus-mask stimulus-onset asynchrony (SOA) varied from 20 to $35 \mathrm{msec}$ when it was fixed, and from 22 to $53 \mathrm{msec}$ when it was taken as the dependent variable for performance fixed at $75 \%$ correct detections. However, at those exposure durations, subjects were able to identify many of the items in the present study (Experiment 1). It is noteworthy that in Doyle and Leach's (1988, Experiment 1) study, a word-superiority effect appeared when their results were averaged across their two SOAs ( 25 and $35 \mathrm{msec}$ ), although their graphs suggest that this effect resulted mainly from the longest SOA.

The third possible factor relates to the different stimuli used. We matched the well- and poorly structured forms on their Fourier spectra. It is possible that in other studies, uncontrolled variations in the spatial frequency components of the stimuli affected performance. Such variations could be important in face-detection experiments, which use just a small number of stimulus configurations. However, it seems less likely to be crucial in word-detection experiments, which rely on a larger population of different items. In the present experiment, the detectability of the stimuli was not influenced by their familiarity but rather by their energy, which was equivalent for the familiar and unfamiliar stimuli. The data obtained by Purcell and Stewart $(1986,1988)$ and Doyle and Leach (1988) may have resulted from a too-long presentation time of the stimuli and/or from masking conditions that sometimes allowed their subjects to perceive the normal face clearly (Purcell \& Stewart, 1988). Future work needs to assess the particular conditions that determine whether familiarity affects detection.

\section{REFERENCES}

Biederman, I. (1987). Recognition by components: A theory of human image understanding. Psychological Review, 94, 115-147.

Bonnet, C. (1986). Visual perception in context. Cahiers de Psychologie Cognitive, 6, 137-155.

BonNeT, C. (1989). La perception visuelle des formes. In C. Bonnet, R. Ghiglione, \& J. F. Richard (Eds.), Traité de psychologie cognitive: Vol. 1. Perception, action et langage (pp. 1-76). Paris: Dunod.

De Valois, R. L., \& De Valois, K. K. (1980). Spatial vision. Annual Review of Psychology, 31, 309-341.

De Valois, R. L., \& De Valois, K. K. (1988). Spatial vision. New York: Oxford University Press.

DOYLE, J. R., \& LEACH, C. (1988). Word superiority in signal detection: Barely a glimpse, yet reading nonetheless. Cognitive Psychology, 20, 238-318.

GiNSBURG, A. P. (1978). Visual information processing based on spatial filters constrained by biological data. Unpublished doctoral dissertation, Report of the Aerospace Medical Research Laboratory, AMRL-TR-78-129.

GINSBURG, A. P. (1986). Spatial filtering and visual form perception. In K. R. Boff, L. Kaufman, \& J. P. Thomas (Eds.), Handbook of perception and human performance: Vol. II. Cognitive processes and performance (pp. 34.1-34.42). New York: Wiley.

Graham, N. (1981). Psychophysics of spatial frequency channels. In M. Kubovy \& J. R. Pomerantz (Eds.), Perceptual organization (pp. 125). Hillsdale, NJ: Erlbaum.

Humphreys, G. W., \& Bruce, V. (1989). Visual cognition: Computational, experimental and neuropsychological perspectives. Hillsdale, NJ: Erlbaum.

MARCEL, A. J. (1983). Conscious and unconscious perception: Experiments on visual masking and word recognition. Cognitive Psychology, 15, 197-237.

Purcell, D. G., \& Stewart, A. L. (1986). The face-detection effect. Bulletin of the Psychonomic Society, 24, 118-120.

Purcell, D. G., \& Stewart, A. L. (1988). The face-detection effect: Configuration enhances detection. Perception \& Psychophysics, 43, 355-366.

RidDoch, M. J., \&uMPhREYS, G. W. (1987). Picture naming. In G. W. Humphreys \& M. J. Riddoch (Eds.), Visual object processing: A cognitive neuropsychological approach (pp. 107-143). Hillsdale, NJ: Erlbaum.

TuRveY, M. T. (1973). On peripheral and central processes in vision: Inferences from an information processing analysis of masking with patterned stimuli. Psychological Review, 80, 1-52.

(Manuscript received February 10, 1990.) 